\title{
The Efficiency of Heuristic Subject-Oriented Learning for Students' Multi-Dimensional Thinking Self-Development
}

\author{
Valentin I. Andreyev ${ }^{1}$ \\ ${ }^{1}$ Kazan (Volga region) Federal University, Kazan, Russia \\ Correspondence: Valentin I. Andreyev, Kazan (Volga region) Federal University, Kremlyovskaya Street 18, \\ Kazan, 420008, Russia.
}

Received: December 29, 2014

Accepted: January 22, 2015 Online Published: February 11, 2015

doi:10.5539/res.v7n4p140

URL: http://dx.doi.org/10.5539/res.v7n4p140

\begin{abstract}
The objective of this article is to substantiate the essence and peculiarities of heuristic subject-oriented learning and its focus on students' multi-dimensional thinking self-development. The relevance of the studied issue connected with students' focus on multi-dimensional thinking self-development is determined by the fact that in actual higher school practice academic thinking makes the core of students' training; it is mainly aimed at cognitive activity, at the same time other types of thinking (system, creative, reflexive, critical, predictive etc.) are generally less developed.

The leading idea of heuristic subject-oriented learning in comparison with traditional training is the development and purposeful application of heuristics and heuristic instructions for students' training aimed to solve tasks and problems of a specific type. The main result of heuristic subject-oriented leaning is students' high level of self-motivation directed at students' multi-dimensional thinking self-development: system, creative, critical, reflexive, predictive, and others. The proceedings of the article may be helpful for teachers of higher schools as peculiarities of heuristic learning are proved by examples of practical application of heuristic instructions to activate students - future teachers' self-development of multidimensional critical thinking.
\end{abstract}

Keywords: heuristic learning, heuristic instruction, multi-dimensional thinking, critical thinking, criteria of thinking multidimensionality evaluation

\section{Introduction}

In modern very difficult socio-cultural and economic situation in the world, the global system crisis is becoming more and more obvious. Crisis phenomena affect different types and areas of human activity, including education. The essence of crisis phenomena in modern higher education is that traditional methods and technologies do not always achieve their objectives, though the requirements to the quality of university graduates are continuously increasing.

This situation makes pedagogues-researchers of the whole world conduct active search of innovative opportunities aimed to improve the quality of higher education; one of the goals of this research is the development and self-development of system, creative, critical, reflexive, predictive and other types of students' thinking.

Modern theory and practice of the Russian higher education focus more and more attention on the subject oriented approach to student's personality to increase the quality of education.

In 1994 the author of this article proved the law of education quality security the essence of which is the following.

Education achieves the guaranteed quality in case if education transforms into self-education, upbringing becomes self-upbringing, and development turns into creative self-development of the personality (Andreyev, 1994).

It is not difficult to notice that this law shows and actualizes attention to the fact that self-abilities and self-processes in student's personal and professional formation are of great importance to secure the quality of education.

Indeed, if to take a process and students' abilities for creative self-development, they make an important but at 
the same time very difficult and multidimensional phenomenon.

Our long-term researches showed that students' creative self-development is a difficult, multidimensional kind of activity of subject - subject orientation the backbone elements of which are abilities of self-knowledge, self-actualization, self-determination, self-government, self-improvement and creative self-realization.

Multidimensionality and as a result multidimensional approach to the solution of modern problems connected with the improvement of education quality and efficiency is one of the basic characteristics of modern scientific pedagogical knowledge, including the knowledge about the development and self-development of different types of thinking peculiar to the modern student.

In this context, it is also necessary to notice that multidimensionality is a fundamental property of nature, society and person's activity. However, multidimensional approach, multidimensional thinking is not always manifested in human activity. Multidimensionality is most often shown as one of fundamental characteristics of advanced human thinking.

If we consider human's ordinary thinking, it is most often shown and realized as one-dimensional thinking. One-dimensionality of human's common consciousness, thinking, and behavior is convincingly revealed in the book of one of the greatest philosophers of the XXth century Herbert Marcuse "One-dimensional man: Studies in the ideology of advanced industrial society" (Marcuse, 1964), published in 1964 in the USA. Herbert Marcuse's points of view stated in this book are as follows.

In modern society most people are identical as the majority of them think one-dimensionally and, therefore, they subject in general to identical desires, aspirations, demands.

Due to the fact that person's ordinary thinking and behavior are mainly one-dimensional, therefore, according to Herbert Marcuse's theory, false, "standard" representations, values and corresponding demands are often imposed on the modern person.

To change the society in the positive way, according to Herbert Marcuse, the "Great refusal" of many false and at the same time one-dimensional determined human needs is necessary. For example, it would be necessary to change the direction of human's needs from nature exploitation towards harmony with it, to focus their desires and feelings on high spirituality, moral and culture. (Markuse, 1964)

In our opinion, one of the basic reasons of modern system crisis in the society, science and education is also connected and determined by one-dimensionality of human consciousness, thinking and behavior in various spheres of human activity, including education.

Our researches show that one of essential characteristics of person's advanced thinking is its multidimensionality. Thus we reveal and determine the essence of multidimensionality as follows.

Multidimensional thinking is a generalized characteristic of such kind of person's thinking which is specified by thinking strategy and tactics multidimensionality, search and application of a set of approaches, methods to solve various, especially creative tasks and problems, and on this basis a selection and implementation of the most optimum and most effective solution.

From the psychological point of view, for example, according to the theory of three-dimensional model of intelligence of the American psychologist D. Guilford, multidimensionality of person's thinking is clearly shown and realized in the course of divergent thinking when creative tasks and problems solving are accompanied by the process of generating and implementation of some strategies, the search of several ways to solve a creative task in different directions is carried out in parallel, i.e. person's multidimensional thinking is realized in fact (Guilford, 1965).

In the 70s of the last century, when the theory of problem training was being developed, the three-dimensional model of the main classes of problem situations and basic characteristics of different types of creative thinking was also presented and proved in the monograph of the Russian psychologist A. M. Matyushkin. Thus, as a result of his research, A. M. Matyushkin also realized and understood the exclusive value of searching many but not one way aimed to solve educational problems and problem situations (Matyushkin, 1972)

Thus, though both D. Guilford and A. M. Matyushkin did not use the concept of "multidimensional thinking", they realized and actualized an extremely important role and value which multidimensionality of thinking strategy and tactics in the solution of creative tasks and various types of problem situations have.

Ideas of multidimensionality, poly-functionality of students' thinking development in their educational activity were often implicitly the object of research both in Russia, and in other countries. 
Let us note some of these ideas. Thus, for example, an American scientist (Targowski, 2011) considers that it is quite possible to develop human wisdom of students in a higher education institution if to stimulate in complex all main functions of thinking: logical and intuitive, creative and critical, system and reflexive, theoretical and practical thinking.

A. Targowski has developed a special course for students "The development of thinking and bases of wisdom".

Important results on identification of psychological-pedagogical conditions of students' critical thinking development in their educational activity can be found in the research (Halpern, 2002). There are also other original, innovative pedagogical approaches to the development of some types of students' thinking in the course of training at the modern higher school (Bever, 2008; Jakel \& Fieber, 2013; Loes et al., 2012; Sheer et al., 2012; Sternberg, 2006).

However, none of the above listed researches has ever set the task of students' pedagogical orientation on self-development of multidimensional thinking in their educational activity.

Our modern researches conducted in this direction show that it is possible to single out the following types of multidimensional thinking:

a) Multidimensional system thinking including such approaches and methods as system-purposeful, system structural, system-functional, and system-cluster.

b) The multidimensional creative thinking determined by the application of various multidirectional heuristic methods of creative tasks and problems solving (brainstorming, synectics, empathy, casual associations, analogies and many other methods and strategies of creative activity).

c) The multidimensional critical thinking based on various strategies and tactics of critical judgments, on the application of various approaches to substantiate critical argument with a support of diverse evaluation judgement criteria.

D) The multidimensional reflexive thinking directed to the perception and understanding of person's merits and vices, his/her interests, motives and demands, specific features of thinking and activity, communication and behavior.

The multidimensional reflexive thinking is especially manifested and it self-develops due to such abilities and self-processes as self-actualization, self-cognition, self-government, self-determination, self-improvement, creative self-realization and self-evaluation in different types and forms of educational and especially design-creative and research activity.

If we consider, for example, creative thinking, it is possible to single out the following criteria of manifestation and evaluation peculiar to the multidimensionality of creative thinking:

1) The ability to actualize and see new problems where others do not see and specify them.

2) The ability to refuse from a trivial, standard or most obvious way to solve a creative task, problem in favor of new, and original, and most effective ones.

3) The ability to generate rather a large number of new ideas, ways of a creative task, problem solving.

4) Manifestation of rich creative imagination in the course of creative tasks and problems solving.

5) Originality of judgments and conclusions.

6) Spatial and temporary multidimensionality of approaches in the explanation of phenomena, processes.

Multidimensionality of thinking is one of indicators that characterizes a high level of thinking with its multidimensional strategies and tactics of thinking, search of various approaches, methods of solutions, and on this basis the selection of the most effective and optimum method to solve the corresponding task, problem

If we further focus attention on the self-development of students' critical thinking multidimensionality, we become aware that it is difficult to overestimate its value for the activity of the modern person.

However, what does the concept "critical thinking" mean? There is a great variety of opinions among scientists concerning its definition (Halpern, 2002)

The American professor, specialist in the development of critical thinking David Klauster considers that "From Kansas to Kazakhstan, from Michigan to Macedonia school teachers and university professors seek ways to develop their students' ability to think critically. We know that critical thinking is something obviously good, a certain skill which will allow us to cope successfully with the requirements of the XXIst century, will help to understand what we study and do" (Klauster, 2013) 
David Klauster identifies the following five signs of pupils' critical thinking manifestation in the course of training:

First, critical thinking is independent thinking. When the lesson is based on the principles of critical thinking, everyone formulates ideas, evaluations, and beliefs irrespective of others.

Secondly, information is a starting but not terminal point of critical thinking.

Thirdly, critical thinking begins with the statement of questions and explanation of problems to solve.

Fourthly, critical thinking strives for the convincing argument. Any argument comprises three basic elements: the statement (also called a thesis, main idea or situation). The statement is backed by a number of arguments. Each argument is in its turn provided with proofs.

Fifthly, critical thinking is social thinking.

Any thought is checked and perfected when it is shared with others" (Klauster, 2013).

Critical thinking is defined by various authors both as a method, and as a technology, and as a philosophical approach, and even as ideology.

In what way is the multidimensionality of critical thinking shown?

As critical thinking is shown and realized in the course of specific tasks solving, and types and kinds of tasks are extremely various and one and the same problem can be solved in various ways, it requires rather a big variety multidimensionality of critical approach, and multidimensionality of critical thinking. Moreover, critical evaluation of events, phenomena most often relies on various, multidimensional criteria. All this generates and demands the application of creative, heuristic approach to the self-development of students' critical thinking multidimensionality in the course of their training.

The generalization of the above listed points of view on the essence of critical thinking allowed us to create and give our own definition of this concept.

Critical thinking is a motivated, conscious, multidimensional criteria-evaluation, cogitative activity demanding identification, evaluation, and the proof of the validity or falsehood, correctness or inaccuracy of theories, provisions, statements in the course of tasks and problems solving, and also demanding evidential reflexive self-evaluation of the validity or falsehood, correctness or inaccuracy of one's own activity, its process and result.

We would like to mention at once that multidimensionality of critical thinking is manifested due to the fact that multidimensionality is realized in a variety of requirements to the solution of various tasks and problems, and also in different types and forms of person's activity:

a) in educational activity, b) professional activity, c) in scientific activity, d) in the social sphere, e) in various situations of person's everyday activity.

The multidimensionality of person's critical thinking is also revealed as critical thinking often demands a high level of the development and the accompanying manifestation of system, creative, reflexive, predictive, and other types of thinking as well.

Heuristic instructions, i.e. instructions, recommendations opening the most productive strategies of students' critical thinking multidimensionality in various tasks and problems solving were especially effective for pedagogical stimulation of multidimensional critical thinking self-development process.

"The heuristic instruction for students' multidimensional critical thinking self-development":

1) Criticizing in a dispute situation, proving your point of view, mentally try to take the opponent's point of view to deeply understand and realize his/her reasons and arguments.

2) Criticizing, choose accurate, necessary and sufficient criteria of evaluation judgments. (The following criteria may be universal criteria: theoretical importance, practical importance, social importance, personal importance, criterion of some system functioning and development efficiency, and so on).

3 ) In the course of proving and denial, and also in the course of any critical judgments, remember about the rules and mistakes in connection with the thesis:

- The thesis has to remain invariable throughout the whole course of proving and denial.

- The substitution of the thesis "the argument to the personality" is not admitted when the activity of a specific person is under discussion but not the thesis. 
- Ambiguity, "blurring" of the thesis is not allowed.

4. Remember about the rules and mistakes in relation to the argument:

- Arguments have to be true and proved judgments.

- Arguments are substantiated independently, i.e. irrespective of the thesis.

- Arguments should not contradict each other.

- Arguments have to be sufficient for the thesis.

5) In the course of critical evaluations and judgments do not make the following mistakes:

- Do not apply to force or threat of force while giving arguments;

- While reasoning, do not resort to and do not use opinions which contradict science;

- While reasoning, do not an appeal to the benefit only because it is profitable in moral, political, economic or status relation to somebody;

- Do not reason to the authority, referring to this authority.

However, it is important not only to carry out creative self-development of critical thinking, it is not less important to know how to carry out criticism and how to react adequately to the criticism of others.

For these purposes, the author of the article has developed and applied special heuristic instructions to activate students' system, creative, reflexive, predictive and critical thinking self-development.

However, the article allows us only to give some examples of heuristic instructions aimed to activate critical thinking multidimensionality self-development.

"Heuristic instruction: how to carry out criticism?"

1) Remember that criticism is not a goal in and of itself, but a means for the improvement of something. In this regard specify the criticism objective.

2) Take into account situational and psychological features of the one who you directly or indirectly criticize.

3) Predict the consequences of your criticism.

4) Use definite and clear criteria of evaluation judgments.

(For example, personal, social or professional importance, objectivity or on the contrary subjectivity of criticism)

5) Always remember about the constructive character of criticism, argumentativeness and validity of your evaluation judgment.

6) Goodwill of tone and style of criticism plays an unimportant role.

7) By all means listen and evaluate counterarguments, the point of view of the one you criticize.

8) Remember that the way you finish criticism is actually important.

"Heuristic instruction: how to react to criticism?"

1) Do not try to deny criticism in your address at once.

2) Do not make excuses referring to circumstances or some accompanying conditions.

3) Until you understand the situation, do not answer criticism with criticism.

4) Agree with evaluation critical judgments addressed to you if they are rather convincing and proved.

5) Do not decline all responsibility in case of constructive criticism.

6) In case of unreasonable and non-constructive criticism, do not provoke a conflict, but give your point of view reasonably.

7) Thank the interlocutor for a constructive conversation and constructive criticism.

8) Remember that multidimensionality of critical thinking does not exclude, but assumes that in the course of evaluation-critical judgments it is also necessary to intensify the application of system, creative, reflexive and predictive thinking.

It is necessary to emphasize that the "Heuristic instructions" formulated above stimulate and set very important and significant, but general strategies of students' self-development in various situations of evaluation-critical activity. These strategies and heuristic methods corresponding to them intensify the processes of students' critical 
thinking multidimensionality self-development; this is achieved if, at least, two conditions are realized:

A) students should be motivated to learn and understand the essence of these "Heuristic instructions";

B) the teacher of a higher school should know and understand clearly the way to stimulate and focus students on the self-development of critical thinking multidimensionality systematically and purposefully.

Therefore, the teacher of a higher school is offered a number of generalized recommendations in the form of "The heuristic instructions" about pedagogical factors and conditions aimed to stimulate students' multidimensional critical thinking self-development in their educational activity.

"The heuristic instruction for the teacher: How to stimulate students' multidimensional critical thinking self-development?"

1) Be ready to reveal different points of view, approaches to the solution of any problem on the basis of academic material selection and designing; apply evaluation-critical judgements.

2) From time to time create debatable situations, the atmosphere of new ideas search; encourage students' independent, original, critical judgments and conclusions in the course of studies.

3) Promote profound understanding of true not imaginary values and meanings of the studied objects, theories, phenomena, and processes.

4) Find problem situations to stimulate students' reflexive evaluation thinking directed to self-analysis and self-assessment of their advantages and disadvantages, self-evaluation of their educational activity outcomes.

5) Encourage students to review the results of other students' micro-researches and project-creative works.

6) Systematically pay students' attention to methods and ways applied to manipulate their consciousness, especially in mass media; develop their own views and judgments of events and processes that take place in the society.

7) Using specific examples, show students the way the constructive criticism differs from faultfinding.

8) Stimulating students' critical thinking multidimensionality self-development, develop their active social position.

The teacher of a higher school should also remember that, focusing students on the self-development of critical thinking multidimensionality, it is necessary to teach them to respect and accept another point of view, to develop tolerance, to appreciate creativity and originality of other people's judgments and conclusions.

\section{Research methods}

The objective of the research determined the methods applied:

1) Theoretical. (There was carried out the analysis of psychological, pedagogical and philosophical literature; modern pedagogical theories and training technologies were compared and synthesized).

2) Empirical. (Pedagogical experiment was carried out. During a semester students- undergraduates of mathematical faculty studied the course "Pedagogics of the higher school"; within the frames of this course they were systematically given various creative, research tasks and problems. There were used methods to stimulate students' self-motivation and aspiration for the self-development of their multidimensional (system, creative, critical, predictive and reflexive) thinking.

At the beginning and at the end of the pedagogical experiment there were assessed students' abilities to apply different types of multidimensional thinking in situations of creative, research tasks and problems solving according to ten-score scale.

\section{Results}

The development of the concept and pedagogical conditions of heuristic training aimed at the self-development of students' multidimensional thinking showed that on the one hand, the teacher should select tasks and problems demanding multidimensional thinking for their solution, and, on the other hand, gradually introduce necessary heuristics and heuristic instructions for their solution.

Explanation and understanding of features peculiar to the following types of thinking: system, creative, critical, reflexive and predictive should play a considerable role in students' multidimensional thinking training.

The results of pedagogical experiment aimed to stimulate the self-development of students' abilities to apply the corresponding types of thinking are the following:

System thinking. (The mean value of students' ability to apply methods of system thinking before the 
pedagogical experiment was 5.85; after the experiment -6.88 ; the probability of the ability change is 0.77 ).

Creative thinking. (It was determined according to students' ability to generate new ideas. The mean value before the pedagogical experiment is 6.69 ; after the experiment -8.12 ; the probability of the ability change is 0.81 ).

Critical thinking. (It was estimated according to the degree of students' evaluation-critical judgments validity in debatable situations. The mean value of the ability before the pedagogical experiment is 6.04; after the experiment $-7,35$; the probability of the ability change is 0.73 ).

Reflexive thinking. (It was estimated according to the degree of students' introspection and self-assessment of their advantages and disadvantages in the course of educational and research tasks performance. The mean value before the pedagogical experiment is 6.04 ; after the experiment- 7.00 ; the probability of the ability change is $0.65)$.

Predictive thinking. (It was estimated in accordance with the degree of forecasting validity of the corresponding events development in problem tasks solving, on the forecasting abilities to promote reasonable hypotheses in the course of educational and research tasks performance. The mean value before the experiment is 5.8; after the experiment-6.9; the probability of the ability change is 0.71 ).

\section{Discussions}

Our researches also show that all above listed types of multidimensional thinking contribute to the success of students' multidimensional thinking development that transforms into self-development of different types of thinking within their learning activity; however, we would like to specify multidimensional reflexive thinking as it activates and intensifies the self-development of all other types of students' multidimensional thinking in conditions of their self-actualization, self-knowledge, self-management, self-improvement and creative self-realization, i.e. in conditions of subject focused educational activity.

Our researches directed to activate students-future teachers' multidimensional thinking self-development within Kazan federal university showed that it is possible to single out a number of factors which really promote this process.

The rating of the factors promoting students' multidimensional thinking self-development is given below (according to the opinion of Master students - future teachers):

1) Knowledge and understanding of essential characteristics, methods, ways of multidimensional thinking (for example, knowledge and understanding of system-purposeful, system-structural, system-functional, system-cluster, creative, critical, reflexive, predictive thinking).

2) Systematic application of a large number of various creative, research tasks and problems demanding a multidimensional approach, multidimensional thinking in the course of their solving.

3) To induce students for multidimensional creative reflection of self-abilities (self-actualization of personal and professional importance of the solved task, abilities to self-knowledge, self-actualization, self-determination, self-government, self-improvement, creative self-realization).

4) Creation of problem, debatable situations the solving of which demands students' multidimensional creative and at the same time critical thinking in the learning process.

5) Systematic involvement of students in various research, design and creative activity with the subsequent review and evaluation of its productivity on the basis of multidimensional criteria.

\section{Conclusion}

The generalization of results of our theoretical - experimental study allows us to draw the following conclusions.

- The efficiency of modern pedagogical theories development and the design of educational technologies may significantly increase if they rely on the ideas of thinking multidimensionality of all subjects taking part in educational activity, especially on the idea of students and teachers' development and self-development of multidimensional thinking.

- At the present stage of the educational systems development, the most perspective is the development of heuristic training, its theory and practice. The essence of heuristic training consists in the development and purposeful application of heuristics, heuristic instructions and methods intensifying students' multidimensional thinking self-development in solving various tasks and problems of subject-focused education. It allows not only to focus students on understanding the importance of thinking multidimensionality but also really launch the mechanisms of activation and intensification of students' abilities for comprehensive creative self-development and creative self-realization, especially in project—creative activity. 


\section{Recommendations}

For systematic activation and intensification of students' multidimensional (system, creative, critical, reflexive and predictive) thinking, it is necessary to reconsider modern seminars and practical training techniques. There should be revealed essential characteristics of multidimensionality of system, creative, critical, reflexive, predictive and other types and forms of practical application of thinking in various situations connected with tasks and educational problems solving. These purposes will require additional development of "heuristic instructions" and their practical application in modern educational activity in the course of tasks solving, organization of students' creative, design-creative, and research activity.

\section{Acknowledgments}

The work is performed according to the Russian Government Program of Competitive Growth of Kazan Federal University

\section{References}

Andreyev, V. I. (1994). Pedagogics for creative self-development. Kazan, Russia: Publishing house of the Kazan university.

Beyer, B. K. (2007). What researt tells us about teaching thinking skills. Social studies, 99(5), 223-232. http://dx.doi.org/10.3200/TSSS.99.5.223-232

Guilford, J. (1965). Three faces of intelligence. In The coll. of research papers: Thinking psychology. M.: Progress.

Halpern, D. (2003). Psychology of critical thinking. S.P.: St.Petersburg

Jakel, A., \& Fider, C. (2013). Introspection in problem solving. Journal of Problem Solving, 6(1), 20-33. http://dx.doi.org/10.7771/1932-6246.1131

Klauster, D. (2002). What is critical thinking? Retrieved from http://testolog .narog. ru/Other $15 . \mathrm{html}$

Loes, C., Pascarella, E., \& Umbah, P. (2012). Effects of diversity experiences on critical thiking skill: Who benefits? Journal of Higher Education, 25.

Marcuse, H. (1964). One-dimensional man: Studies in the Ideology of advanced industrial society.

Matyushkin, A. M. (1972). Problem situations in thinking and training. M.: Pedagogics.

Scheer, A., Noweski, C., \& Meinel, C. (2012). Transforming Constructivist Learning into Action: Design thinking in education. Design and Technology Education, 17(3), 8-19. Retrieved from http://ois.lboro.ac.uk/ois/index.php/article/view/1758/1648

Sternberg, R. (2006). The Nature of Creativity. Creativity Research Journal, 18(1), 87-98. http://dx.doi.org/10.1207/s15326934crj1801_10

Targowski, A. (2011). Cognitive informatics and wisdom development: Interdisciplinary approaches. New York, USA: Western Michiqan University. http://dx.doi.org/10.4018/978-1-60960-168-3

\section{Copyrights}

Copyright for this article is retained by the author(s), with first publication rights granted to the journal. This is an open-access article distributed under the terms and conditions of the Creative Commons Attribution license (http://creativecommons.org/licenses/by/3.0/). 